\title{
O conceito de arquitetônica na teoria bakhtiniana: uma abordagem historiográfica, filosófica e dialógica
}

\author{
Inti Anny Queiroz \\ Universidade de São Paulo (USP), São Paulo, São Paulo, Brasil \\ inti.queiroz@gmail.com
}

DOI: http://dx.doi.org/10.21165/el.v46i2.1506

\begin{abstract}
Resumo
Nossa reflexão busca abordar o conceito de arquitetônica a partir de um olhar historiográfico, filosófico e dialógico, desde sistemas filosóficos anteriores, para, com isso, compreender como esse conceito se estabelece nas obras de Mikhail Bakhtin, teórico ao qual nos filiamos nesta pesquisa. Na primeira parte deste artigo, abordaremos o conceito de arquitetônica em Aristóteles e Immanuel Kant. Na segunda parte, analisaremos o conceito em Bakhtin, buscando assim demonstrar como foi construído na reflexão do filósofo.
\end{abstract}

Palavras-chave: arquitetônica; filosofia da linguagem; ética.

The architectonic concept in Bakhtin's theory: historiographical, philosophical and dialogic approach

\begin{abstract}
Our reflection seeks to address the architectonic concept based on historiographical, philosophical and dialogic approaches, from previous philosophical systems to, thereby, understand how this concept is established in the works of Mikhail Bakhtin, the theorist to whom we join in this research. In the first part of this paper, we discuss the architectonic concept in Aristotle and Immanuel Kant. In the second part, we analyze the concept in Bakhtin's works, thus seeking to demonstrate how it was built in his philosophical reflections.

Keywords: architectonic; philosophy of language; ethics.
\end{abstract}

\section{Introdução}

O Dicionário de filosofia, do filósofo espanhol Ferrater Mora (2000, p. 195), traz em seus verbetes um longo descritivo do conceito de arquitetônica em que traça historicamente um percurso de suas significações. De acordo com Ferrater Mora, o conceito é de ordem filosófica e em boa parte dos casos está relacionado à sistematização de cada método filosófico em si e às reflexões da ética e da filosofia moral. Ele foi utilizado ao longo da história da filosofia por diversos filósofos antigos e modernos.

Por conta da proposta deste estudo, que busca demonstrar a construção do conceito da arquitetônica na obra do russo Mikhail Bakhtin, achamos pertinente tratar inicialmente o conceito a partir de dois renomados filósofos, Aristóteles e Kant. Em seguida, partiremos para o foco principal deste estudo, a arquitetônica na obra do pensador russo. 


\section{A arquitetônica em Aristóteles e Kant}

Aristóteles emprega o conceito de arquitetônica de formas distintas e em diversas partes de seu tratado Ética a Nicômaco (1985), considerada a obra fundadora da ética enquanto ciência prática, e que busca "o estudo das vidas felizes de contemplação e de liderança política, das virtudes, da amizade e do prazer." (COOPER, 2010, p. 439). O filósofo grego considera que "certas artes estão subordinadas a outras de acordo com a relação entre meios e fins [...] e o bem parece pertencer à arte principal e verdadeiramente mestra ou arquitetônica" (FERRATER MORA, 2000, p. 195). A arte, entendida pelos gregos como ciência e o princípio de bem diretamente relacionado ao conceito de arquitetônica, indica que esta tem um caráter de "saber organizador", estando diretamente relacionada ao todo da reflexão aristotélica na obra Ética a Nicômaco, isto é, à ética. O conceito de arquitetônica pode ser considerado fundamental, por ser evidenciado logo nas primeiras linhas, traduzido em português como a "arte principal" de que todas as outras artes ou ciências práticas teriam finalidade. Esta é definida por Aristóteles como a ciência política entendida de forma ampla.

O filósofo grego inicia a obra tratando da questão principal da Ética em que todas as ações "visam a algum bem" e como "há muitas atividades, artes e ciências, suas finalidades também são muitas", porém, as finalidades das principais "devem ter precedência sobre as finalidades das outras". Tal finalidade suprema deve ser o bem e o "melhor dos bens" e este é o objeto da ciência (arquitetônica) soberana e predominante sobre tudo, relativa à ciência política. Esta determina quais seriam as demais ciências e suas finalidades e quais devem ser estudadas numa cidade. A finalidade deste bem serve para um indivíduo e até mesmo para sua família, mas é ainda mais nobre e completa se servir especialmente à comunidade e à cidade. A finalidade suprema do bem é o bem viver que também pode ser traduzido como a felicidade (eudaimonia) e é o objeto da ciência (arquitetônica) que engloba todas as ciências práticas.

Esta ciência suprema foi definida desde Platão como a ciência política num sentido mais amplo, porém, é só em Aristóteles que esta é estabelecida como arquitetônica e visa o bem viver em comunidade. Para Aristóteles, o conjunto das ciências práticas que visam os costumes, a ética e a política compõe a ciência política no sentido amplo e representa a "filosofia das coisas humanas", também conhecida como a sabedoria prática compreendida de um modo mais amplo. Para Aristóteles, a ética estava subordinada à política, pois o ser que age no mundo enquanto ato individual só existe de fato na vida em sociedade.

O leitor não deve estranhar que Aristóteles diga política e não ética. Para o Estagirita, a ética tratou da ação e do bem no âmbito do indivíduo, é apenas uma ciência prática acessória e subordinada à política, a ciência prática maior; na medida em que o ser humano é um animal político, isto é, tem sua essência e se atualiza e realiza-se em ato (energeia) exclusiva e necessariamente na vida em sociedade no estado, o bem mais excelente, o nobre e o justo acabam por ser objetos da política e não da ética. Ontologicamente, o indivíduo isolado não é, não existe, embora exista biologicamente e psicologicamente, determinando a necessidade da ética. (BINI, 2007, p. 38). 
O filósofo alemão Immanuel Kant utilizou o conceito de arquitetônica no penúltimo tópico do último capítulo de sua importante obra Crítica da razão pura (1781). O tópico intitulado "A arquitetônica da razão pura" é iniciado com a seguinte reflexão "Por arquitetônica eu entendo a arte dos sistemas." (KANT, 2012, p. 600). A arquitetônica para Kant é antes de tudo a arte de construção desse novo sistema filosófico que parte dos conhecimentos da razão pura. Porém, deve ser considerada também um sistema organizador das categorias da razão humana, isto é, a arquitetônica seria um sistema organizador das categorias da razão pura independentes de experiência, isto é, a priori. A arquitetônica é a "doutrina do científico em nosso conhecimento geral" (KANT, 2012, p. 600), faz parte da doutrina do método (transcendental) e "contém o fim e a forma do todo que lhe é congruente" (idem), isto é, arquitetônica é a parte formal de uma ideia da razão pura que dá forma à razão prática.

Por arquitetônica eu entendo a arte dos sistemas. Uma vez que a unidade sistemática daquilo que o conhecimento comum transformou primeiramente em ciência, isto é, fazendo de um mero agregado daquele um sistema, a arquitetônica é a doutrina do científico em nosso conhecimento em geral e pertence necessariamente, portanto, à doutrina do método. [...] Por sistema, contudo, eu entendo a unidade dos conhecimentos diversos sob uma ideia. Este é o conceito racional da forma de um todo, na medida em que por meio dele sejam determinados a priori tanto o âmbito do diverso como a posição das partes entre si. Assim, o conceito científico da razão contém o fim e a forma do todo que lhe é congruente. [...] A ideia necessita de um esquema para sua realização, de uma essencial diversidade e ordem das partes que tenha sido determinada a priori a partir do princípio do fim. O esquema que não é projetado segundo uma ideia, mas empiricamente, fornece uma unidade técnica, ao passo que aquele que só surge em decorrência de uma ideia (onde a razão fornece os fins a priori e não os espera empiricamente) funda uma unidade arquitetônica. (KANT, 2012, p. 600-601).

Kant propõe a criação de um sistema de filosofia como uma disciplina por meio de um novo método que depende inicialmente apenas da ideia e que será organizado arquitetonicamente e assim comporá um sistema teórico e doutrinal. Das faculdades humanas parte o sistema das críticas da razão pura e prática. Enquanto isso, do sistema doutrinal surgem a natureza e os costumes ou liberdades. Kant busca respostas para uma série de perguntas feitas ao longo de toda Crítica da Razão Pura e, com isso, propõe construir esse novo método da doutrina transcendental. É possível dizer que, para ele, a arquitetônica é base estrutural-formal de seu sistema de razão pura e traz consigo, como parte do todo, a ideia moral máxima e esta, como independente de experiência, está na razão pura. Entretanto, ainda que esta ideia seja parte da razão pura, é na razão prática que está de fato em diálogo com a ética, com a realização de uma moral na vida prática ou como ele trata em sua metafísica dos costumes. Ao compreender a arquitetônica como a "arte dos sistemas" da razão pura, Kant demonstra que, para ele, ao contrário de Aristóteles, a arquitetônica é parte da estrutura formal do conhecimento científico. A matéria resultante desse pensamento está condicionada ao que vem a posteriori, às experiências, à vida. A razão pura e a razão prática são momentos relativamente autônomos. Sua visão formal da arquitetônica, pensada na razão pura, isto é, a priori, nos leva a seu diálogo com Aristóteles que, ao contrário dele, compreendia a arquitetônica como uma faculdade suprema, mas que era também adquirida ao longo do tempo a partir das práticas. 
Para o entendimento da arquitetônica kantiana, é necessária a compreensão do todo da obra, incluindo não apenas as três críticas, mas também as obras: Fundamentação da Metafísica dos Costumes e a Metafísica dos Costumes. O entrelaçamento de conceitos previstos em seu sistema é a cada obra detalhado, cuidadosamente explicado e inserido em seu sistema filosófico. A arquitetônica deve ser pensada em Kant como a "arte dos sistemas", ou como "a teoria do que existe de científico no nosso conhecimento em geral” (LALANDE, 1999, p. 88). A arquitetônica do sistema filosófico kantiano pode ser entendida tanto como a arte de construir racionalmente um sistema filosófico científico, quanto a ideia do todo da razão humana que compreende este sistema científico geral (e neste caso também, como em Aristóteles, uma ciência suprema ou faculdade dominante).

A razão humana é por sua natureza arquitetônica, considera todos os conhecimentos como pertencentes a um sistema possível e por isso permite também somente aqueles princípios que pelo menos não tornem um conhecimento projetado incapaz de coexistir, em qualquer sistema, com outros em conjunto. (KANT, 2012, p. 397).

\section{A arquitetônica em Bakhtin}

Mikhail Mikháilovitch Bakhtin era estudante recém egresso do curso de estudos clássicos na então Universidade de Petrogrado quando publicou o pequeno texto "Arte e responsabilidade" (doravante AR), na revista $O$ dia da arte em 1919. Neste breve ensaio, Bakhtin inicia a reflexão sobre o que viria a ser o conceito, ao pensar na arquitetônica como algo que relaciona no ser a ética (vida) e a estética (arte/criação): "Arte e vida não são a mesma coisa, mas devem tornar-se algo singular em mim, na unidade da minha responsabilidade" (BAKHTIN, 2010b, p. XXXIV). No texto, o conceito de arquitetônica ainda não aparece, porém, o breve texto já prepara o leitor para a base do conceito, largamente abordado em sua obra seguinte Para uma filosofia do ato responsável, escrita entre os anos 1920-21. Especialistas na teoria bakhtiniana afirmam que AR abre o projeto de um livro de filosofia moral nunca concluído e publicado, que incluiria este e outros dois textos do período: Para uma filosofia do ato responsável e $O$ autor e a personagem na atividade estética. Bakhtin abre AR falando sobre o que seria a arquitetônica mesmo sem usar essa expressão.

Chama-se mecânico ao todo se alguns de seus elementos estão unidos apenas no espaço e no tempo por uma relação externa e não os penetra a unidade interna do sentido. As partes desse todo, ainda que estejam lado a lado e se toquem, em si mesmas são estranhas umas às outras. Os três campos da cultura humana - a ciência, a arte e a vida só adquirem unidade no indivíduo que os incorpora à sua própria unidade. [...] $\mathrm{O}$ que garante o nexo interno entre os elementos do indivíduo? Só a unidade da responsabilidade. Pelo que vivenciei e compreendi na arte, devo responder com minha vida para que todo o vivenciado e compreendido nela não permaneçam inativos. [...] Arte e vida não são a mesma coisa, mas devem tornar-se algo singular em mim, na unidade da minha responsabilidade. (BAKHTIN, 2010b, p. XXXIII-XXXIV).

É relevante perceber que, no trecho acima, Bakhtin opera com duas importantes categorias amplamente trabalhadas em Kant, o tempo e o espaço. No entanto, ele evidencia que essas categorias na forma kantiana são categorias mecânicas quando estão unidas numa relação externa, isto é, em Kant são apenas de ordem formal e lógica. 
Assim, estas não penetram a "unidade interna do sentido" que se dá no ser em ato e situado historicamente. Para Bakhtin, esta "penetração" acontece de forma prática, no ato, enquanto para Kant apenas na razão pura. O teórico russo retoma as categorias kantianas e as une com a unidade interna do sentido que está contida no ser, através de seu lugar único no mundo, um lugar que é espacial e exotópico, temporal e histórico, e pleno de valores axiológicos da relação deste ser com o mundo.

No último período de $\mathrm{AR}$, Bakhtin evidencia que "Arte e vida não são a mesma coisa, mas devem tornar-se algo singular em mim, na unidade da minha responsabilidade." (BAKHTIN, 2010b, p. XXXIV). É possível dizer que arte (compreendida por Bakhtin como algo concreto e esteticamente realizado pelo homem) e vida (como algo dado e de ordem ética), devem tornar-se, isto é, realizar um movimento de processo para algo transformado, que é "singular em mim" por meio do meu ser, "na unidade da minha responsabilidade". Somente eu, do lugar que ocupo, respondo por meus atos e sou responsável por eles e assim construo novas possibilidades para a arte e para a vida. Esse processo de "dever tornar-se", isto é, de transformação de algo que já existe em algo novo, pressupõe o que Bakhtin trabalhará detalhadamente em sua obra seguinte Para uma filosofia do ato responsável (doravante PFA).

Em PFA, os três momentos essenciais da arquitetônica de Bakhtin aparecem a todo instante, os valores, o tempo e o espaço, mas é o produto da atividade estética e seu sentido no mundo da vida que motivam o texto desde o início.

Também a atividade estética não consegue ligar-se a esta característica do existir (ser) que consiste na sua contingência e no seu caráter de evento aberto; e o produto da atividade estética, no sentido que lhe é próprio, não é o existir em seu efetivo devir, e, no que concerne à sua existência, ele se integra no existir mediante o ato histórico de uma ativa percepção estética. [...] Somente na sua totalidade, tal ato é verdadeiramente real, participa do existir-evento [...] é incorporado na unidade singular do existir que vai se realizando. (BAKHTIN, 2010d, p. 41-42).

Bakhtin continua o texto tratando de um ponto essencial no entendimento tanto deste quanto de AR quando fala das diferenças dos mundos da vida e da cultura. Para ele, o mundo da cultura é "o mundo no qual se objetiva o ato da atividade de cada um" (BAKHTIN, 2010d, p. 43), isto é, o mundo de nossas atividades individuais, singulares. Já o mundo da vida é aquele em que "tal ato realmente, irrepetivelmente, ocorre". (idem, p. 43). No ato-evento do existir, o ser "reivindica a completa e definitiva autodeterminação na unidade de um determinado domínio do sentido - da ciência, da arte, da história" (idem, p. 42). Sua exposição busca, em boa parte das vezes, refutar as teorias de Kant que é nomeado abertamente ou mesmo retomado pela expressão "pensamento teórico". Um dos pontos centrais dessa refutação é a questão do dever do ser em seu ato responsável. O dever é visto por Bakhtin como um dos aspectos que nos levam à arquitetônica.

Não existe um dever estético, científico e, ao lado deles, um dever ético: há apenas o que é estética, teórica e socialmente válido e ao qual se pode agregar um dever a respeito do qual todas estas validades são de caráter técnico, instrumentais. Tais posições adquirem sua validade no interior de uma unidade estética, científica sociológica; enquanto adquirem o dever na unidade de minha vida singular e responsável. [...] O dever é uma categoria original do agir ato (postuplenie - postupok) e 
tudo é um ato meu, inclusive o pensamento e o sentimento, é uma certa atitude (ustanovka) da consciência, cuja estrutura nos propomos a desvendar fenomenologicamente. [...] (BAKHTIN, 2010d, p. 47-48)

Ainda que Bakhtin trabalhe com pensamento e sentimento, coloca o homem em relação constante com o mundo concreto que o cerca. Para ele, o pensamento também representa um ato no existir.

Mas o mundo como objeto de conhecimento teórico procura fazer passar como o mundo como tal, isto é, não só como unidade abstrata, mas também como concretamente único em sua possível totalidade; o conhecimento teórico visa, assim, construir uma filosofia primeira (Prima philosofia) na forma de gnosiologia teórica. (BAKHTIN, 2010d, p. 50).

Para ele, o grande problema na teoria da razão de Kant está justamente em considerar que o momento de conteúdo-sentido é apenas uma unidade teórica abstrata como juízo de validade universal, isto é, um juízo puramente teórico que não leva em conta os aspectos concretos da vida, históricos e individuais do ser (autor, tempo, circunstância e unidade moral de sua vida, seus valores). Ele evidencia que é no ato responsável do ser que os elementos teóricos e os elementos da vida se unem em uma relação de vida e cultura. Para Bakhtin, o ato não é mera circunstância proveniente de um juízo racional como para Kant, e sim uma escolha concreta no mundo, de um ser único, dotado de emoção e desejo, historicamente situado, com valores axiológicos e que tem neste ato total responsabilidade consigo e com o outro. A experiência influencia o ato do ser. Ao contrário de Kant, ele coloca a ética na razão prática, na realidade, na vida, na experiência.

É necessário reconduzir a teoria em direção não a construções teóricas e à vida pensada por meio destas, mas ao existir no evento moral, em seu cumprir-se real - à razão prática - o que, responsavelmente, faz quem quer que conheça, aceitando a responsabilidade de cada um dos atos de sua cognição em sua integralidade, isto é, na medida em que o ato cognitivo como meu ato faça parte, com todo o seu conteúdo, da unidade da minha responsabilidade, na qual e pela qual eu realmente vivo e realizo atos. (BAKHTIN, 2010d, p. 58).

Bakhtin parte então para a definição de ato responsável de fato e da apresentação dos pontos de seu método filosófico. Para ele, o ato entendido como produto e processo (ergon e energeia) deve ser considerado não só por seu conteúdo, "Mas na sua própria realização - de modo algum conhece, de modo algum possui o existir unitário singular da vida; orienta-se por ele e considera sua completude - seja no seu aspecto conteudístico, seja na sua real facticidade singular do interior." (idem, p. 79). O ato é resultado da prática e pressupõe uma escolha de fundamento ético.

O ato é o resultado final, uma consumada conclusão definitiva; concentra, correlaciona e resolve um contexto único e singular e já final o sentido e o fato, o universal e o individual, o real e o ideal, porque tudo entra na composição de sua motivação responsável, o ato constitui o desabrochar da mera possibilidade na singularidade da escolha uma vez por todas. (BAKHTIN, 2010d, p. 80).

Todavia, ainda que Bakhtin busque inicialmente a construção de uma filosofia moral, o aspecto da linguagem já intrigava o pensador que entendia a importância do produto estético da comunicação humana como a relação do ser com o mundo. Ele diz 
que a linguagem deve ser "muito mais adaptada para exprimir exatamente esta verdade do que revelar o aspecto lógico abstrato na sua pureza." (idem, p. 83). Isto é, pela linguagem não falamos apenas palavras, falamos verdades (ou mentiras).

A definição de ato ético responsável, assim como a teoria bakhtiniana da moral, vai se construindo aos poucos ao longo da obra, e com afirmações cada vez mais fortes e concretas. Para Bakhtin, a vida não tem álibi. "O ato responsável é precisamente o ato baseado no reconhecimento desta obrigatória singularidade. É essa afirmação do meu não álibi no existir que constitui a base da existência" (idem, p. 99). Ele compreende que o ser em sua posição ativa-responsiva é responsável por seus atos na vida que acontece por meio da linguagem.

Pouco antes do trecho que ele chama de "Primeira parte", em que faz uma análise do poema de Pushkin, Bakhtin apresenta a estrutura de sua metodologia de análise da "arquitetônica do mundo real do ato ético".

A primeira parte do nosso estudo será dedicada precisamente à análise dos momentos fundamentais da arquitetônica do mundo real, não enquanto pensado mas enquanto vivido. A parte seguinte será dedicada à atividade [dejanie] estética como ação, não a partir do interior do seu produto, mas do ponto de vista do autor enquanto participante responsável, e a ética da criação artística. A terceira parte será dedicada à ética política, e a última à religião. (BAKHTIN, 2010d, p. 115).

O trecho citado nos faz crer que, de fato, este texto é parte inicial do projeto de uma grande obra de filosofia moral que buscava descrever esta arquitetônica, mas pode ser também um projeto inicial que o levaria posteriormente à sua teoria de filosofia da linguagem e da cultura, pois apresenta uma metodologia de análise de um corpus literário. Por conta das dificuldades pessoais em relação ao também difícil contexto russo do período, este projeto acabou não se concretizando. Contudo, na compreensão de sua obra como um todo, isto fica ainda mais evidente.

O mundo no qual o ato se orienta fundado na sua participação singular no existir: este é o objeto da filosofia moral. [...] ele tem a ver somente com uma pessoa única e com um objeto único [...] que lhes são dados em tons emotivos-volitivos individuais. [...] Mas estes mundos concreto-individuais, irrepetíveis de consciências que realmente agem, têm alguns componentes em comum: não nos conceitos de leis gerais, mas no sentido de momentos comuns das suas arquitetônicas concretas. É esta arquitetônica do mundo real do ato que a filosofia moral deve descrever, não como um esquema abstrato, mas como o plano concreto do mundo do ato unitário singular, os momentos concretos fundamentais de sua construção e da sua disposição recíproca. Estes momentos fundamentais são: eu-para-mim, o outro-para-mim, e eu-para-o-outro; todos os valores da vida real e da cultura se dispõem ao redor destes pontos arquitetônicos fundamentais do mundo real do ato: valores científicos, estéticos, políticos (incluindo também os éticos e sociais) e finalmente religiosos. (BAKHTIN, 2010d, p. 114).

Fica claro que aqui Bakhtin não apenas fundamenta o objeto de sua filosofia moral, mas também mais uma vez refuta Kant quando coloca a arquitetônica como um elemento estrutural-relacional concreto de seu sistema filosófico de uma maneira completamente diversa do filósofo alemão, que percebe a arquitetônica apenas na razão pura. Para o russo, a arquitetônica do mundo real é o objeto de descrição da filosofia moral e ao evidenciar que "esta arquitetônica do mundo real do ato que a filosofia moral 
deve descrever" assim relaciona este mundo como aquele "no qual o ato se orienta fundado na sua participação singular no existir". Isto é, a arquitetônica acontece no ato e em relação a outros seres no existir. Este ato relaciona valores ideológicos (do que mais tarde ele chamaria de esfera/campo) de seres concretos nos momentos arquitetônicos: eu-para-mim, o outro-para-mim, e eu-para-o-outro, envoltos em valores e que acontecem de forma singular no tempo e no espaço.

É possível dizer que, neste ponto, Bakhtin apresenta seu primeiro método e faz sua primeira análise com este método. Sua metodologia de análise trazia uma ordem organizacional que levava em conta: vida, arte, autoria, ética, política e religião e está dividida em quatro passos. Primeiro deve ser feita uma análise da arquitetônica do contexto social mais amplo e da vida. Depois uma análise estética, ética e exotópica da obra ou enunciado, levando em conta a autoria e a relação deste autor-criador com o mundo e outros seres. Posteriormente, uma análise ética da política e, quando for o caso, uma análise de fatores místicos ou religiosos. Na obra PFA, ele realiza esta análise no poema lírico Separação (Razluka) de Pushkin. Porém, antes disso, diferencia a análise por meio não de um ato estético, mas sim na vida. Para nossa pesquisa, bem como para a compreensão da teoria bakhtiniana como um todo, é relevante atentarmos ao método de análise proposto por Bakhtin neste ponto de PFA. Compreender "como um todo arquitetônico é disposto em torno de mim como único centro de realização do meu ato".

Para minha consciência ativa e participante, esse mundo, como um todo arquitetônico, é disposto em torno de mim como único centro de realização do meu ato; [...] me realizo em minha ação visão, ação pensamento, ação-fazer prático. Em correlação com o meu lugar particular que é o lugar do qual parte a minha atividade no mundo, todas as relações espaciais-temporais pensáveis adquirem um centro de valores em volta do qual compõem num determinado conjunto arquitetônico concreto estável e a unidade possível se torna singularidade real. [...] Este centro não é imanente [...] No interior do sistema, cada componente desta unidade é logicamente necessário mas o sistema em si no seu todo é apenas algo relativamente possível; é somente em correlação comigo, enquanto penso ativamente, somente em correlação com o ato do meu pensamento responsável que tal sistema se incorpora na real arquitetônica do mundo vivido, como seu momento, se enraíza na sua real singularidade, significativa como valor. (BAKHTIN, 2010d, p. 118-120).

A citação acima descreve bem qual é o teor do conceito bakhtiniano de arquitetônica que começa a ser desenhado em PFA. O ser ativo e participante entende que é parte do diálogo com outros seres e de forma responsável, ativa e criativa participa do mundo da vida e da cultura. Aqui também dialoga diretamente com Kant, porém refuta a ideia de que a arquitetônica está na razão pura quando diz que "este centro não é imanente" e que o sistema em si só é possível em correlação com o ser no mundo da vida. Enquanto para Kant a arquitetônica é a arte dos sistemas da razão pura, e está na ideia formal, para Bakhtin a arquitetônica só existe no ato, na relação com o ser no mundo da vida e em relação com outros seres, pois é este que dá sentido à arquitetônica do mundo vivido e faz acontecer a partir dos valores que coloca em seus atos de comunicação, isto é, em seu existir-evento como ser único e historicamente situado. 
Em sua obra seguinte, o ensaio $O$ problema do conteúdo, do material e da forma na criação literária (doravante PMCF), escrito entre os anos de 1923-24, presente no livro Questões de literatura e estética (2010a), Bakhtin continua a reflexão ao apresentar o conceito de forma arquitetônica. Estas podem estar situadas na arte nos "valores morais e físicos do homem estético", na natureza "no seu ambiente", na vida no "acontecimento no seu aspecto da vida particular, social, histórica e etc.". As formas arquitetônicas são "aquisições, realizações", são "formas de existência estética na singularidade". As formas arquitetônicas são as formas do conteúdo e determinam as formas composicionais.

As formas arquitetônicas são as formas dos valores morais e físicos do homem estético, as formas da natureza enquanto seu ambiente, as formas do acontecimento no seu aspecto da vida particular, social, histórica, etc.; todas elas são aquisições, realizações, não servem a nada, mas se auto-satisfazem tranquilamente, são as formas de existência estética na sua singularidade. (BAKHTIN, 2010a, p. 25).

Os conceitos de ato, autoria, arquitetônica e domínio cultural estão presentes em PMCF e, com isso, continua a construção de sua teoria, que agora traz um tom não mais filosófico-moral, mas sim filosófico-estético. Para ele, "deve-se distinguir rigorosamente [...] o conteúdo, momento indispensável no objeto artístico" (BAKHTIN, 2010a, p. 21). Este conteúdo é em sua base ético. O domínio ético é essencial nessa relação e equivale à vida, ao pessoal, ao político e ao social. $\mathrm{O}$ objeto artístico deve ser pensado a partir de sua função social no mundo da cultura. A forma arquitetônica constitui a unidade cultural.

[...] objeto estético em sua singularidade e estrutura puramente artística, por meio do método teleológico ${ }^{1}$. Compreender teleologicamente a estrutura da obra e como o objeto estético se realiza. Assim compreende-se como ocorre a criação da forma composicional derivada da forma arquitetônica. [...] As formas arquitetônicas principais são comuns a todas as artes e a todo o domínio da estética, elas constituem a unidade deste domínio. (BAKHTIN, 2010a, p. 25-26).

Assim como em PFA, Bakhtin traz novamente a reflexão sobre a singularidade do criador e o conceito de domínio que, posteriormente, em outras obras do Círculo, seria chamado de esfera, campo ou sistemas ideológicos constituídos. No capítulo $O$ problema do conteúdo do ensaio PCMF, ele desenvolve o que seria o início efetivo de sua teoria da cultura e mostra que está diretamente relacionada à questão dos domínios, do ponto de vista (ideológico) e da criação arquitetônica. Ele demonstra como, a partir das unidades arquitetônicas, são compostos os domínios ou campos ideológicos.

O problema deste ou daquele domínio da cultura no seu conjunto - conhecimento, ética, arte - pode ser compreendido como o problema dos limites desse domínio. Este ou aquele ponto de vista criador, possível ou realizado de fato, só se torna necessário e indispensável de modo convincente quando relacionado com outros pontos de vista

\footnotetext{
${ }^{1}$ É relevante ressaltar o que é o teleológico na história da filosofia. O termo começou a ser usado na Grécia por Anaxágoras. Depois foi amplamente utilizado por Sócrates, Platão e Aristóteles. Sua significação principal é a finalidade e as causas das coisas. Os filósofos escolásticos medievais utilizaram o termo para provar a existência de Deus. O termo foi retomado na filosofia moderna em Kant para este fim, quando desenvolve o juízo teleológico de que se não podemos provar a inexistência de Deus, pode ser que ele exista.
} 
criadores: só quando nas suas fronteiras nasce a necessidade absoluta desse ponto de vista, em sua singularidade criativa, é que ele encontra seu fundamento e sua justificação sólida. (BAKHTIN, 2010a, p. 29).

No capítulo "O problema do material", Bakhtin aprofunda as reflexões sobre a criação estética e traz novamente o conceito de arquitetônica quando diz que "é importante compreender justamente a originalidade do objeto estético, como tal, e a originalidade da ligação puramente estética dos seus elementos, ou seja, de sua arquitetônica" (BAKHTIN, 2010a, p. 54). Contudo, esta ligação puramente estética não deve ser entendida como uma relação formal, como vimos na discussão em PFA. Bakhtin continua a entender a obra como um centro organizador de sentido que relaciona diversos fatores, os momentos arquitetônicos. Estes são plenos de vida e determinados pelo sujeito do ato ético-estético, o autor-criador da obra.

No conjunto das obras do Círculo, PCMF pode ser considerada a primeira proposta de reflexão de estética da criação verbal, ainda que em diversos momentos do texto outras linguagens artísticas sejam citadas, como a música, o teatro e as artes visuais. Todavia, o ensaio pode ser compreendido como uma evolução das duas reflexões anteriores em que Bakhtin estava mais preocupado com questões de filosofia moral no ato e na vida. Ainda que, no final de PFA, ele traga uma análise a partir de um poema lírico de Pushkin e compreenda que o ato ético acontece de forma ainda mais concreta no ato de produção estética, é só neste ensaio que ele se entrega à linguagem. Em PCMF, Bakhtin começa a mostrar sua relação cada vez maior com os estudos das linguagens da cultura, de sua análise do homem-sujeito e suas relações no mundo ético e estético, através de suas relações com a linguagem e o mundo social. Para compreender as considerações sobre arquitetônica deste período, devemos levar em conta reflexões contidas na obra seguinte, $O$ autor e a personagem na atividade estética (doravante APAE), escrita entre os anos de 1924 e 1927, em que Bakhtin desenvolveu mais profundamente conceitos já elencados nos textos anteriores, como a compreensão da autoria na obra literária e as relações do autor com o herói.

Bakhtin abre o ensaio APAE com o conceito de arquitetônica e, num diálogo com os textos anteriores, o relaciona imediatamente com a questão da autoria. Aqui fica ainda mais clara a diferença entre a criação literária e o ato no mundo vivido. A relação entre o autor e a personagem da obra literária auxiliou Bakhtin a repensar sua teoria arquitetônica. A partir de APAE, a arquitetônica deve ser também pensada na obra literária como "fundamento geral e de princípio quanto nas peculiaridades individuais" do autor. A relação entre o autor e a personagem é uma relação arquitetônica.

A relação arquitetonicamente estável e dinamicamente viva do autor com personagem deve ser compreendida tanto em fundamento geral e de princípio quanto nas peculiaridades individuais de que ela se reveste nesse ou naquele autor, nessa ou naquela obra. [...] É especificamente estética essa resposta ao todo da pessoapersonagem, e essa resposta reúne todas as definições e avaliações ético-cognitivas e lhes dá acabamento em um todo concreto-conceitual singular e único e também semântico. Essa resposta total à personagem tem um caráter criador produtivo e de princípio. De modo geral, toda relação de princípio é de natureza produtiva e criadora. $O$ que na vida na cognição e no ato chamamos de objeto definido só adquire determinidade na nossa relação com ele: é nossa relação que define o objeto e sua estrutura e não o contrário [...] a resposta total, que cria o todo do objeto, realiza-se de forma ativa, mas não é vivida como algo determinado, sua determinidade reside 
justamente no produto que ela cria, isto é, no objeto enformado; o autor reflete a posição volitivo-emocional da personagem e não a sua própria posição em face à personagem (BAKHTIN, 2010b, p. 3-5).

No trecho, além da redefinição de arquitetônica para pensar a obra literária, é possível também perceber novamente o diálogo com Kant. Ao dizer que é nossa relação com o objeto que o define, Bakhtin mostra a influência do filósofo alemão. Porém, é preciso perceber que esta relação sujeito-objeto, para Bakhtin, está presente na produção estética (que é também ética) da obra literária e relaciona o autor-criador à personagem no objeto estético. Para Bakhtin, a relação sujeito que comanda o objeto acontece na obra literária, mas é uma relação em que o autor reflete as vontades e as emoções da personagem.

Completamos esta breve reflexão sobre as obras de Bakhtin com seu livro sobre Dostoiévski. A terceira obra do período dos anos 1920 foi publicada em 1929 com o título Problemas da Obra de Dostoiévski e em sua edição atual (publicada na União Soviética inicialmente em 1963) recebe o nome de Problemas da Poética de Dostoiévski (doravante PPD). É na publicação de 1963 que Bakhtin insere os trechos sobre as relações dialógicas, criando novas nuances em seu próprio método e disciplina que ele chama de Metalinguística. O trecho abaixo nos remete indiretamente à arquitetônica ao operar com as relações e as categorias lógicas do discurso que tem autor-criador e enunciado concreto. Para que a arquitetônica aconteça numa singular produção de sentido, é necessário um "momento dialógico".

As relações dialógicas são irredutíveis às relações lógicas ou às concreto-semânticas, que por si mesmas carecem de momento dialógico. Devem personificar-se na linguagem, tornar-se enunciados, converter-se em posições de diferentes sujeitos expressas na linguagem para que entre eles possam surgir relações dialógicas. A vida é boa. A vida não é boa. Estamos diante de dois juízos revestidos de determinada forma lógica e um conteúdo concreto-semântico (juízos filosóficos acerca do valor da vida) definido. Entre esses juízos há certa relação lógica: um é a negação do outro. Mas entre eles não há nem pode haver quaisquer relações dialógicas, eles não discutem absolutamente nada entre si (embora possam propiciar matéria concreta e fundamento lógico para a discussão). Esses dois juízos devem materializar-se para que possa surgir relação dialógica entre eles ou tratamento dialógico deles. Assim, esses dois juízos, como uma tese e uma antítese, podem unir-se num enunciado de um sujeito, que expresse a posição dialética deste em relação a um dado problema. Nesse caso não surgem relações dialógicas. Mas se esses dois juízos forem divididos entre dois diferentes enunciados de dois sujeitos diferentes, então surgirão entre eles relações dialógicas. [...] Para se tornarem dialógicas, as relações lógicas e concreto-semânticas devem, como já dissemos, materializar-se, ou seja, devem passar a outro campo da existência, devem tornar-se discurso, ou seja, enunciado, e ganhar autor, criador de dado enunciado cuja posição ele expressa. (BAKHTIN, 2010c, p. 209-210).

Para Bakhtin, as relações dialógicas "penetram toda a linguagem humana" (idem, p. 47), isto é, penetram o discurso. São evidenciadas no contraponto lógico dos sentidos. Remetem a valores em embate, não apenas em discursos em diálogo, mas a discursos anteriores, posteriores, visões de mundo de ordem histórica, personificada no ser através de discursos. Os discursos das diversas personagens de Dostoiévski foram um laboratório para esta reflexão. Os diferentes tipos de discursos, mesmo os monológicos, serviram de ponto de partida para a percepção de que havia um diálogo que acontecia 
muito além do perceptível. As relações dialógicas estão nas entrelinhas do texto, no discurso, e ganham vida na interação. "Somente quando contrai relações dialógicas essenciais com as ideias dos outros é que a ideia começa a ter vida" (BAKHTIN, 2010c, p. 96).

É a partir desta obra que Bakhtin começa a compreender o fenômeno da carnavalização da linguagem que, nos anos 1940, dá o tom de sua obra sobre Rabelais. Bakhtin reserva boa parte do quarto capítulo de PPD para discutir gêneros clássicos e contemporâneos que apresentaram a cosmovisão carnavalesca.

Já tivemos oportunidade de falar das particularidades da estrutura da imagem carnavalesca. Esta tende a abranger e a reunir os dois polos do processo de formação ou os dois membros da antítese: nascimento-morte, mocidade-velhice, alto-baixo, facetraseiro, elogio-impropério, afirmação-negação, trágico-cômico, etc. e o polo superior da imagem biunívoca reflete-se no plano inferior segundo o princípio das figuras das cartas do baralho. Isso pode ser expresso assim: os contrários se encontram, olham-se mutuamente, refletem-se um no outro, conhecem e compreendem um ao outro. (BAKHTIN, 2010c, p. 204).

Ao demonstrar os variados "dois membros da antítese", Bakhtin busca preparar seu leitor para a reflexão sobre as relações dialógicas. A antítese tratada aí é não apenas uma referência à dialética discursiva, mas principalmente ao começo da compreensão de que discursos em interação sempre trazem tons diferentes, signos ideológicos e referentes diferentes. A diferença produz sentido e faz com que os sentidos sejam organizados também por diferenças. As diferenças são evocadas no discurso, recebem sentido não no sistema linguístico, mas na organização da comunicação no mundo real, têm história, tempo, espaço e, principalmente, autoria. Com isso, é possível dizer que a arquitetônica, como organizadora de sentidos, realizada a partir de momentos arquitetônicos, também leva em conta essas antíteses nas relações que permitem a criação de um enunciado. No todo arquitetônico de um enunciado não há apenas o discurso e as intenções de sentido de um determinado autor historicamente situado, há também outros discursos contrastantes de outros autores, de tempos anteriores, auxiliando na construção de um novo enunciado projetado para um novo diálogo no futuro. Nas relações dialógicas, a tensão dialógica se faz presente assim como nas relações da vida cotidiana. Elas refletem e refratam discursos da vida e tomam forma nas esferas da atividade humana. As relações de interação previstas nos momentos arquitetônicos, pensadas por Bakhtin desde PFA (eu-para-mim, outro-para-mim, eupara-outro), fazem ecoar vozes temporais e atemporais, no pequeno e no grande tempo, e são personificadas em um dado enunciado concreto, que tem função específica no mundo social, e são corporificadas num domínio cultural.

A reflexão sobre as relações dialógicas nos remete a seu livro sobre a obra de Rabelais, que busca completar o que hoje podemos chamar uma proposta de filosofia da cultura iniciada em PFA. Faz parte do todo arquitetônico da obra bakhtiniana o entendimento do conceito de cultura permeado ao longo da obra Cultura popular da idade média e no renascimento: o contexto de François Rabelais (doravante CPIM) (BAKHTIN, 2008). Devemos compreender a cultura como parte constitutiva da arquitetônica, pois a organização de sentidos nas unidades culturais acontece em relação direta com cada domínio cultural num determinado tempo-espaço. A cultura está nas fronteiras, no diálogo com outras culturas, com outras formas de produção do mundo, 
como bem pontuou Bakhtin em PCMF. Mas para que exista esta cultura é preciso pensar que ela só existe no conjunto de unidades culturais de uma determinada comunidade semiótica e no conjunto de enunciados produzidos em uma dada esfera cultural. A unidade cultural pressupõe, em seu todo construído, como que mônadas que refletem e refratam uma dada cultura. Bakhtin compreendia que estas são produzidas e organizadas no momento de criação, no ato do autor em seu tom emotivo-volitivo como pontuado na obra "O Autor e a personagem na atividade estética". Para Bakhtin, a cultura é compreendida de forma ampliada, estando nas fronteiras entre as esferas da atividade humana. A cultura permeia tudo, reflete e refrata tudo, é ativada por forças centrífugas e centrípetas, mas é no homem e pelo homem que a cultura é transformada em enunciado concreto e ganha vida no mundo. Este é o mundo da cultura.

A cultura oficial de que Bakhtin trata em CPIM era específica do período medieval, porém, pode ser entendida no grande tempo da história, como a cultura hegemônica das manifestações institucionais, não apenas do Estado, mas também da elite intelectual de um determinado tempo e espaço, geralmente uma cultura de base erudita, esteticamente complexa. Para a elite cultural da era moderna em diante, apenas no período das festas carnavalescas era permitido o riso, o cômico, o grotesco. Isso parece ainda acontecer na contemporaneidade. É relevante notar que, na carnavalização, não apenas o mundo acontece às avessas e as hierarquias sociais não são as mesmas, mas também novas produções de sentido são permitidas e novos gêneros surgem por conta da ordem fora do padrão hegemônico.

$\mathrm{O}$ riso e a visão carnavalesca do mundo, que estão na base do grotesco, destroem a seriedade unilateral e as pretensões de significação incondicional e intemporal e liberam a consciência, o pensamento e a imaginação humana, que ficam assim disponíveis para o desenvolvimento de novas possibilidades. Daí que uma certa "carnavalização" da consciência precede e prepara sempre as grandes transformações, mesmo no domínio científico. (BAKHTIN, 2008, p. 43).

Se de fato a carnavalização prepara para grandes transformações de valores ao mostrar uma possibilidade de um mundo às avessas, seria essa carnavalização uma possibilidade de maior liberdade criativa que teria influência na arquitetônica das unidades de cultura? Devemos retomar aqui o que Bakhtin compreende por arquitetônica como um centro organizador do sentido, que utiliza categorias de espaço, tempo e valores do ser historicamente situado e em interação ética para a produção estética. A carnavalização pode ser entendida como um fator que amplia a liberdade estética desse ser criador para a composição de um novo objeto estético, pois este não está mais totalmente determinado por valores da cultura hegemônica vigente num certo tempo histórico e, assim, novas possibilidades de arquitetônica podem surgir.

Para finalizar este estudo sobre a arquitetônica bakhtiniana, achamos relevante trazer o texto Os gêneros do discurso, escrito no início dos anos 1950. Neste ensaio, Bakhtin desenvolve profundamente sua teoria do enunciado concreto ao compreender a relação entre a oração e o enunciado, isto é, das pequenas produções de sentido num texto e seu todo. Nesta obra de sua fase mais madura, em nenhum momento ele menciona o conceito de arquitetônica, porém é possível escutar os ecos do conceito em todo o texto, particularmente nos momentos conclusivos. Se a arquitetônica organiza o sentido de modo sistemático, envolvendo forma, conteúdo, autoria, valores, tempo, espaço, é possível dizer que os gêneros do discurso atuam como formas concretas das 
diversas possibilidades arquitetônicas. O gênero como "formas relativamente estáveis e típicas de construção do todo" arquitetônico.

Falamos apenas através de determinados gêneros do discurso, isto é, todos os nossos enunciados possuem formas relativamente estáveis e típicas de construção do todo. Dispomos de um rico repertório de gêneros de discursos orais (e escritos). Em termos práticos, nós os empregamos de forma segura e habilidosa, mas em termos teóricos podemos desconhecer inteiramente a sua existência. (BAKHTIN, 2010b, p. 282).

Nosso questionamento fica ainda mais evidente quando, no final do texto, ele coloca que "Os gêneros do discurso são modelos tipológicos de construção da totalidade discursiva" (BAKHTIN, 2010b, p. 334) ou mesmo quando ele fala que o enunciado é "um conjunto de sentidos" (idem, p. 329). Nos dois trechos, ele traz respectivamente as ideias de "construção da totalidade" e "conjunto de sentidos". Ambas nos remetem à arquitetônica.

O conceito de Arquitetônica não é restrito a ele, mas deve ser pensado no conjunto do entendimento de outros conceitos e ideias da teoria bakhtiniana, bem como das reflexões dos demais pensadores do chamado Círculo de Bakhtin e compõe, por meio desta reflexão, as relações dialógicas e sua importância no mundo da cultura, para a constituição do mesmo. Os conceitos de esfera, autoria, ato responsável, responsabilidade, gêneros do discurso são parte da construção da arquitetônica das ideias do Círculo e auxiliam no entendimento da própria arquitetônica.

\section{Considerações finais}

O conceito de arquitetônica foi utilizado por diversos filósofos ao longo da história. Originalmente tratado por Aristóteles na obra Ética a Nicômaco, referindo-se à ciência política como a ciência arquitetônica suprema, condicionava outras ciências práticas a esta, dentre elas, a ética e a política como prática social e relacionava, dentro de sua ética, uma série de outros conceitos pertinentes à arquitetônica. Em Kant, a arquitetônica foi pensada como um dos fatores principais para a criação de uma concepção de filosofia teórica. Significava a "arte dos sistemas" da razão pura, estava diretamente condicionada à estrutura formal do conhecimento a priori e não demandava a experiência para que pudesse criar esquemas de pensamento da razão pura.

Em nossa pesquisa, trabalhamos com o conceito nas principais obras de Mikhail Bakhtin, que compreende a arquitetônica de duas formas, e com claras influências de Aristóteles e Kant. O filósofo russo, ao mesmo tempo, refutava e ressignificava as teses destes filósofos anteriores. De Aristóteles veio não apenas o conceito em si, mas principalmente a compreensão de que a arquitetônica compreende o todo dos nossos atos sociais, que são responsáveis para com a polis ou a coletividade de seres. Para Aristóteles, o ato como produto do homem estava diretamente condicionado ao bem da polis e por isso é um ato que pressupõe a ética. O mesmo acontece em Bakhtin, porém aqui o ser em seu ato responsável responde ao outro nos momentos arquitetônicos (eupara-mim, eu-para-o-outro, outro-para-mim).

Também de Aristóteles vem a ideia da arquitetônica como um saber maior organizador que relaciona o conhecimento teórico com a prática social. A influência de Kant acontece em forma de refutação e ressignificação em boa parte das relações 
teóricas entre eles, como vimos no início deste tópico. Entretanto, as categorias lógicas de tempo e espaço como condicionantes da base da arquitetônica em Bakhtin tornam-se ponto chave para compreender o conteúdo e não mais a forma, como foi visto no filósofo alemão. Também de Kant vem a ideia da arquitetônica como sistema estruturante do pensamento; para Bakhtin, esse pensamento é transformado em ato e concretizado na vida em forma de um enunciado concreto. Enquanto que para Kant ele estava apenas na ideia abstrata teórica, isto é, na razão pura, para Bakhtin encontra-se na razão prática.

A arquitetônica bakhtiniana pode ser entendida de duas formas. Por um lado, a arquitetônica é um conceito sistematizador superior que engloba todas as categorias filosóficas bakhtinianas de compreensão de mundo, isto é, a composição da malha conceitual da teoria. Por outro, ela compreende a organização do sentido no todo englobante de um enunciado concreto que é realizado num ato responsável, enquanto potência no ser único e sempre em relação de interação com o outro, com a esfera ideológica, num determinado tempo-espaço. Nos dois casos, a arquitetônica deve ser pensada em relação ao todo da cultura, com parâmetros éticos e estéticos e que se realizam nas práticas sociais interativas/discursivas. A arquitetônica organiza o sentido do objeto estético, seja ele um objeto de arte ou qualquer outro gênero discursivo da comunicação humana.

\section{REFERÊNCIAS}

ARISTÓTELES. Ética a Nicômaco. Tradução, notas e introdução de Mario da Gama Kury. Brasília: Editora da UnB, 1985.

BAKHTIN, M. M. A cultura popular na idade média e no renascimento: o contexto de François Rabelais. Tradução de Yara Frateschi Vieira. 6. ed. São Paulo: Hucitec, 2008.

O problema do conteúdo, do material e da forma na criação literária. In:

Questões de literatura e de estética. São Paulo: Hucitec, 2010a. p. 13-70. Fontes, 2010b.

. Estética da criação verbal. Tradução de Paulo Bezerra. São Paulo: Martins

. Problemas da poética de Dostoiévski. Tradução de Paulo Bezerra. 5. ed. Rio de Janeiro: Forense Universitária, 2010c [1963].

. Para uma filosofia do ato responsável. Tradução de Valdemir Miotello e Carlos Faraco. São Carlos: Pedro \& João Editores, 2010d [1920-24].

BINI, E. Notas. In: ARISTÓTELES. Ética a Nicômaco. Bauru: Edipro, 2007.

COOPER, J. M. A comunidade política e o bem supremo. In: ZINGANO, M. Sobre a Ética Nicomaqueia de Aristóteles. Textos selecionados. São Paulo: Odysseus, 2010. p. 439-491.

FERRATER MORA, J. Dicionário de Filosofia. Tomo 1. São Paulo: Loyola, 2000.

LALANDE, A. Vocabulário técnico e crítico da filosofia. São Paulo: Martins Fontes, 1999. 
KANT, I. Crítica da razão pura. Tradução e notas de Fernando C. Mattos. Petrópolis: Vozes; Bragança Paulista; São Paulo: Editora da Universidade São Francisco, 2012.

Recebido em: 30/07/2016

Aprovado em: 27/03/2017 